\title{
BONDING ABILITY OF LADLE SLAGS
}

\author{
Miroslava KLÁROVÁ, Jozef VLČEK, Michaela TOPINKOVÁ, Jiří BURDA \\ VSB - Technical University of Ostrava, Ostrava, Czech Republic, EU, miroslava.klarova@vsb.cz
}

https://doi.org/10.37904/metal.2021.4230

\begin{abstract}
Both Energetic and Metallurgy industry produce large amount of fine grain waste products. Thanks to their properties and composition these waste substances can be recycled back in their original production, where they become from. A typical characteristic of discussed materials is their fineness, and thus their difficult manipulativeness. For their successful regeneration in an original production, it is necessary to densify them into bigger pieces like briquettes or pellets. The research described below in this article focusing on investigation of bonding system, which would be possible to use for compactation of chosen waste products. Usage of ladle slags as a bonding system is not very well explored area. It was found out, that for example ladle slags play a good role as a bonding compound in process of briquette making with addition of fine grain metal bearing wastes. A compressive strength of prepared briquettes was of value $46 \mathrm{MPa}$ after water hydration and $125 \mathrm{MPa}$ in the case of alkali activation. Iron content was changeable depending on amount of specific used raw material. Some tested materials used in this project contain more than $90 \mathrm{wt} \%$ of iron oxides, so it can be concluded, they are based on them. Any content of conventional binder participates on composition of prepared briquettes. Chemical and mineralogical composition of studied raw materials and briquettes was identified by XRFS, XRD methods. A calorimetric measurement of waste hydration heat and determination of cold compressive strength after 2,7 and 28 days were also applied.
\end{abstract}

Keywords: Ladle slag, bonding system, metal-bearing waste

\section{INTRODUCTION}

It is possible to solidify fine grain waste materials mostly thanks to use of conventional binder as it is a Portland cement. Composition of Portland cement is usually not suitable for considered recycling of waste materials back in plant where they were formed. At the same time, usage of conventional binder creates costs, which play significant role in profit of treatment of waste products $[1,2]$.

A consideration of direct use of some waste product as a binder is then offered for given purpose. Blast furnace slag and its properties, as well as its various usability are very well known. On the contrary, a use of steel slags as a binder is rarely widespread nowadays. Because of that a proved research focusing right on steel slags, especially on verification of their bonding ability [3].

A bonding ability of steel slags was studied by the method of alkali activation and water hydration of chosen slags.

If the slag should be alkali activated, it is desirable to achieve its latent hydraulic activity. It means, it is necessary to have an amorphous structure, which is possible to achieve by its fast cooling. A higher glassy phase content, better latent hydraulic properties will slag show. At lower glassy phase content, the slag can be alkali activated only in the case of contribution of minerals like merwinite, respectively dicalcium silicate in beta form $\left(\beta-\mathrm{C}_{2} \mathrm{~S}\right)$. Another important factor is a content of $\mathrm{CaO}$, which decides about type and form of hydraulic products, and so about hydraulic or latent hydraulic character of slag. As a possibly alkali activatable can be considered that slag, which contains low or zero amount of $\mathrm{CaO}$. At higher $\mathrm{CaO}$ content it is necessary to balance its content by high enough amount of $\mathrm{SiO}_{2}$ for achieving slag latent hydraulicity [4]. 
It is important mainly a mineralogical composition of slag for its possibility of hydration. In the case of this type slags it is not an aim to achieve an amorphous structure, but gaining of a maximal content of water hydratable minerals, mainly $\beta-\mathrm{C}_{2} \mathrm{~S}$. Slags hydrated by water very often contain minerals, which represents also Portland cement composition. For usage of hydraulic properties of slags there is important also content of other minerals as $\mathrm{C}_{3} \mathrm{~S}$ (tricalcium silicate), $\mathrm{C}_{3} \mathrm{~A}$ (tricalcium aluminate), $\mathrm{C}_{4} \mathrm{AF}$ (brownmillerite), $\mathrm{C}_{12} \mathrm{~A}_{7}$ (mayenite), $\mathrm{C}_{2} \mathrm{~F}$ (dicalcium ferrite), less significant are minerals $\mathrm{C}_{3} \mathrm{MS}_{2}$ (merwinite) and $\mathrm{C}_{2} \mathrm{AS}$ (ghelenite) $[4,5]$.

\section{EXPERIMENT AND DISCUSSION}

A bonding ability of steel slags, especially ladle slags, was verified by the method of alkali activation by water solution of sodium silicate or by addition of tap water. Chemical composition of slags and briquette samples was carried out by method of X-Ray Fluorescence, mineralogical composition determined X-Ray Diffraction, and thermal activity of sags was observed by titration calorimetry. Buk density was carried out by the method of saturation of samples in distilled water and cold compressive strength was determined according to standard ČSN EN 12350 - 3.

\subsection{Raw materials}

Metal bearing wastes from metallurgy rated among the group of materials with high iron content, where belong for example iron scales, sludges, flyes. Their chemistry shows Table 1. It is obvious that iron content in used waste materials varies between 34 and $94 \mathrm{wt} \%$.

Table 1 Chemical composition of used metal bearing wastes (wt\%)

\begin{tabular}{|c|c|c|c|c|c|c|c|}
\hline $\begin{array}{c}\text { Waste } \\
\text { material no. }\end{array}$ & Type of waste material & $\mathbf{C a O}$ & $\mathrm{Al}_{2} \mathrm{O}_{3}$ & $\mathrm{SiO}_{2}$ & $\mathbf{M g O}$ & $\mathrm{Fe}_{2} \mathrm{O}_{3}+\mathrm{FeO}$ & $\mathrm{MnO}$ \\
\hline $\mathrm{A}$ & iron scales & 6.01 & 2.31 & 10.71 & 0.93 & 75.12 & 1.10 \\
\hline $\mathrm{B}$ & sludges & 6.84 & 0.17 & 1.67 & 1.34 & 85.74 & 1.20 \\
\hline $\mathrm{C}$ & dust from grinding and blasting & 1.64 & 0.52 & 1.49 & 0.44 & 93.63 & 0.57 \\
\hline $\mathrm{D}$ & grinded waste from crowbars & 0.11 & 4.41 & 0.67 & $<0.01$ & 90.42 & 0.85 \\
\hline $\mathrm{E}$ & waste material from desulphurization & 26.55 & 2.53 & 12.34 & 8.43 & 34.06 & 1.11 \\
\hline
\end{tabular}

Steel slags, which were studied, differ in their origin, type of aggregate, where they were formed. Conditions of slags formation reflect mainly in their chemical and phase composition and granulometry as well. Some slags were taken in liquid state from steel ladle and cool down controlled, some of them were taken directly after pouring out of ladle. Others were sampled from mounds and could age of several weeks and could came into contact with water or air humidity. A chemical composition of used slags summarizes Table 2.

Table 2 Chemical composition of studied ladle slags (wt\%)

\begin{tabular}{|c|c|c|c|c|c|c|}
\hline Ladle slag no. & $\mathrm{CaO}$ & $\mathrm{Al}_{2} \mathrm{O}_{3}$ & $\mathrm{SiO}_{2}$ & $\mathrm{MgO}$ & $\mathrm{Fe}_{2} \mathrm{O}_{3}+\mathrm{FeO}$ & $\mathrm{MnO}$ \\
\hline $\mathrm{S} 1$ & 54.63 & 19.43 & 11.52 & 5.50 & $1.95+1.89$ & 4.00 \\
\hline $\mathrm{S} 2$ & 50.59 & 17.69 & 19.39 & 7.52 & $0.30+0.56$ & 1.58 \\
\hline $\mathrm{S} 3$ & 55.62 & 21.83 & 12.55 & 4.99 & 1.72 & 0.40 \\
\hline $\mathrm{S} 4$ & 61.76 & 16.28 & 11.66 & 5.02 & 0.45 & 0.10 \\
\hline $\mathrm{S} 5$ & 55.70 & 12.75 & 20.32 & 5.39 & 0.59 & 0.40 \\
\hline
\end{tabular}

It is obvious from the chemical composition, that most of slags contain high amount of $\mathrm{CaO}$ and relatively low amount of $\mathrm{SiO}_{2}$. Because of this fact one cannot account with formation of glassy phase in bigger quantity. 
A phase composition depends on chemical composition and thermal history of given slag. Studied slags composed mainly of $\mathrm{CaO}, \mathrm{SiO}_{2}$ and $\mathrm{Al}_{2} \mathrm{O}_{3}$ oxides. In the case of ladle slags these three oxides create typically up to $80 \%$ of total volume, where the remaining part typically holds magnesium oxides, manganese oxides, but also iron oxides and others. Just these minor components form crystalline phase detectable on X-Ray diffraction record. A significant fact is that some of newly created minerals show hydraulic properties. In the case when the slag was after sampling cooled down rapidly, it can be expected also presence of specific part of glassy phase. Mineralogical composition of studied slag brings Table 3.

Table 3 Mineralogical composition of studied ladle slags

\begin{tabular}{|c|c|c|c|c|c|}
\hline \multirow{2}{*}{ Mineral } & \multicolumn{5}{|c|}{ Ladle slag no. } \\
\hline & 1 & 2 & 3 & 4 & 5 \\
\hline$\beta-C_{2} S$ & $x$ & $x$ & & $x$ & $\mathrm{x}$ \\
\hline$\gamma-\mathrm{C}_{2} \mathrm{~S}$ & & $\mathrm{x}$ & $x$ & & $\mathrm{x}$ \\
\hline $\mathrm{C}_{3} \mathrm{MS}_{2}$ (merwinite) & $x$ & & & & $\mathrm{x}$ \\
\hline $\mathrm{C}_{2} \mathrm{MS}_{2}$ (akermanite) & $x$ & $x$ & & & \\
\hline $\mathrm{C}_{2} \mathrm{AS}$ (ghelenite) & & $\mathrm{x}$ & & $\mathrm{x}$ & \\
\hline $\mathrm{C}_{4} \mathrm{AF}$ (brownmillerite) & $\mathrm{x}$ & & & $\mathrm{x}$ & \\
\hline $\mathrm{C}_{12} \mathrm{~A}_{7}$ (mayenite) & & & $x$ & $x$ & $\mathrm{x}$ \\
\hline $\mathrm{CAS}_{2}$ & & & & $x$ & \\
\hline $\mathrm{MgO}$ & & $x$ & $x$ & $\mathrm{x}$ & $\mathrm{x}$ \\
\hline $\mathrm{CaO}$ & & & $x$ & & $x$ \\
\hline
\end{tabular}

A main mineral which should be contained for the purpose of water hydration is $\beta-C_{2} S$. In general, slags determined to water hydration contain minerals which create also composition of Portland cement which means, except $\beta-C_{2} S$, also for example brownmillerite and mayenite presented in slags no. 3, 4 and 5 .

\subsection{Bulk density and cold compressive strength}

One of parameters by which a bonding ability of slags was evaluated was their bulk density and next one cold compressive strength during hydration process in season after 2; 7 and 28 days. Mixtures for sampling consisted of grounded chosen slags (milling for increasing of specific surface, $300 \mathrm{~m}^{2} . \mathrm{kg}^{-1}$ determined by Blain method), water glass as an activator and water, respectively just water without water glass. Observation of bulk density was carried out due to monitoring of possible positive or negative volume change of slags, what would be reason of slags disintegration. After 28 days of hydration a bulk density was recorded in range $2.0-$ $2.3 \mathrm{~g} \cdot \mathrm{cm}^{-3}$ in the case of alkali activated slags, respectively between $1.7-2.1 \mathrm{~g} \cdot \mathrm{cm}^{-3}$ after water hydrated slags. Moderate increase in bulk density was observed in time, which could be caused by formation of new hydrated phases. In some cases, even decrease in bulk density was recorded. In both cases these changes were not significant enough to cause disintegration of samples.

Cold compressive strength as another evaluating parameter was determined in the same stages of hydration process as it was bulk density, and so after 2; 7 and 28 days. Measured data are presented in Table 4. In this case it is obvious that samples containing ladle slags do not show very high levels after alkali activation comparing to others waste products (not included in an article), especially comparing to blast furnace slag. While alkali activated blast furnace slag typically showed strength after 28 days of hydration up to $88 \mathrm{MPa}$, in the case of ladle slag it was between 16 and $87 \mathrm{MPa}$, which are lower but satisfying levels. 
Table 4 Cold compressive strength

\begin{tabular}{|c|c|c|c|c|c|c|}
\hline \multirow{2}{*}{ Ladle slag no. } & \multicolumn{5}{|c|}{ Cold compressive strength (MPa) } \\
\cline { 2 - 7 } & \multicolumn{3}{|c|}{ Alkali activation } & \multicolumn{3}{c|}{ Water hydration } \\
\cline { 2 - 7 } & $\mathbf{2}$ days & $\mathbf{7}$ days & 2 days & $\mathbf{7}$ days & 2 days & $\mathbf{7}$ days \\
\hline S1 & 53.6 & 66.8 & 66.6 & 2.7 & 5.5 & 10.9 \\
\hline S2 & 64.2 & 95.6 & 87.5 & 26.0 & 29.2 & 29.9 \\
\hline S3 & 49.5 & 50.0 & 50.5 & 3.1 & 3.5 & 4.8 \\
\hline S4 & 39.2 & 42.5 & 46.7 & 3.7 & 6.7 & 11.9 \\
\hline S5 & 17.2 & 18.7 & 16.6 & 8.4 & 9.0 & 12.4 \\
\hline
\end{tabular}

A big difference in strength between slags alkali activated and slags hydrated by water is caused by a phase composition of slags. Most of them do not contain big enough amount of water hydratable minerals. By the way an interesting level of strength showed slags no. 1, 2, 4 and 5, of which strength levels after 28 days of hydration (hydration by water) were higher than $10 \mathrm{MPa}$. In the case of slag no. 2 it was even almost $30 \mathrm{MPa}$. Mentioned slags contain a significant part of hydraulically active mineral $\beta-C_{2} S$ and / or others water hydratable mineral like $\mathrm{C}_{12} \mathrm{~A}_{7}, \mathrm{C}_{3} \mathrm{MS}_{2}, \mathrm{C}_{4} \mathrm{AF}, \mathrm{CaO}$ and $\mathrm{MgO}$.

Hydration of these waste materials causes a presence of the same minerals which can be find in Portland cement. The lowest strength after water hydration among other slags showed slag no. 3 , in spite of that fact its strength level ensures a manipulative strength, means high enough to possible next operation with solidified samples.

\subsection{Calorimetry - heat of hydration}

A progress in hydration processes of studied slags was observed by calorimetric method. Achieved results then gave another base for evaluation of samples prepared by solidification, were chosen slags acted as a binder. For given purpose, materials were fine grain milled (specific surface $300( \pm 15 \%) \mathrm{m}^{2} \cdot \mathrm{kg}^{-1}$ ). Water was added to dried sample according to experience achieved during sampling for hydration by water. After water application to sample they reacted together and at the same time the voltage which represents quantitative expression of total size of thermal change in sample was recorded. Hydration curves were constructed from that mentioned values, their trend shows Picture 1 and also hydration heat was calculated. Values of hydration heat introducesTable 5.

Table 5 Hydration heat of ladle slags after 24 hours

\begin{tabular}{|l|c|c|c|c|c|c|}
\hline Ladle slag no. & S1 & S2 & S3 & S4 & S5 & Cement CEM I 42.5R \\
\hline Hydration heat $\left(\mathrm{J} \cdot \mathrm{g}^{-1}\right)$ & 138.52 & 159.32 & 150.28 & 111.06 & 172.03 & 225.7 \\
\hline
\end{tabular}

On Figure 1 below it is obvious that ladle slags 1, 3, 4 similarly show a rapid increase of hydration heat and after its release in several minutes the hydration can be no longer observed. Comparing to cement CEM I $42,5 \mathrm{R}$, which was also included in to experiment, it is very well visible that in this case hydration takes longer time.

Ladle slag no. 5 behaved similarly to cement. In this case a gradual increase of thermal heat was recorded in first few minutes and its total determined hydration heat in 24 hours is higher comparing to other tested slags. 


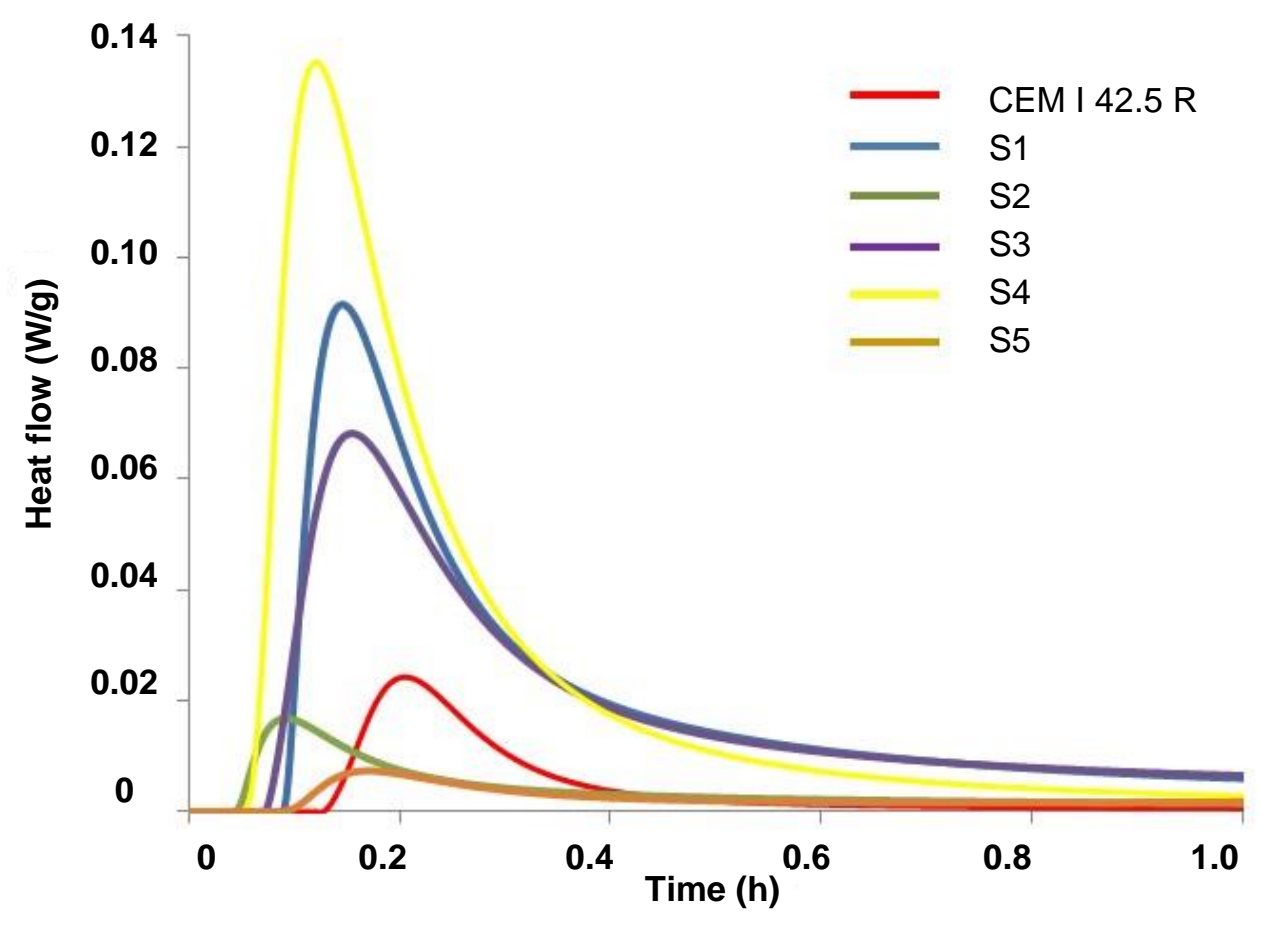

Figure 1 Trend of increase of hydration heat of ladle slags in first 60 minutes

\subsection{Briquetting}

Most waste materials, which are potentially recyclable, eave their primary manufacturing plant as very fine grain products. But that fineness causes difficulties in manipulation and their potential next treatment. Solidification is one of suitable method which allow to eliminate that essential issue and agglomeration, palletisation or briquetting of these materials are methods used with advantage.

Based on previous analyses were selected for briquetting ladle slags 4 and 5 due to their character. Evaluation of bonding ability of slags was carried throughout determination of bulk density and cold compressive strength of prepared tested samples - briquettes.

Table 6 Composition, bulk density and cold compressive strength of prepared briquettes

\begin{tabular}{|c|c|c|c|}
\hline Briquette & $\begin{array}{c}\text { Briquettes composition } \\
(-)\end{array}$ & $\begin{array}{c}\text { Bulk density } \\
\left({\left.\mathrm{g} . \mathrm{cm}^{-3}\right)}^{-}\right.\end{array}$ & $\begin{array}{c}\text { Cold compressive } \\
\text { strength } \\
(\mathrm{MPa})\end{array}$ \\
\hline B1 & S4, D, B & 3.04 & 3.96 \\
\hline B2 & S5, D, B & 3.07 & 6.57 \\
\hline B3 & S4, C, B & 3.05 & 3.44 \\
\hline B4 & S4, C, A, B & 2.54 & 3.24 \\
\hline B5 & S5, C, A, B & 2.56 & 2.73 \\
\hline B6 & S4, C, E, B & 2.64 & 2.38 \\
\hline B7 & S5, C, E, D, B & 2.84 & 1.95 \\
\hline B8 & S4 (higher content), C, B & 3.26 & 4.85 \\
\hline B9 & S5 (higher content), C, B & 3.12 & 3.13 \\
\hline
\end{tabular}

Slags were used as a binder for mixtures with high iron content. An activation of bonding component was carried only by adding water into mixture. The reason was followed purpose of usage of given briquettes as 
recyclable fine grain metal bearing waste for example in Blast furnace or as a part of charge to steelmaking furnace. Besides, saving of natural iron raw materials necessary for industrial production is also considered and necessity of reduction of alkali raw materials part (e.g. water glass would bring it in to mixture, despite the fact it gained higher mechanical parameters) as well. Used metal bearing wastes from metallurgy are typical in their high iron content, fine grain structure and these are for example wear dust, scales, converter sledges, etc. a composition of briquettes and values of achieved bulk density and cold compressive strength after 28 days of hydration summarizes in average next Table 6 . An iron content, as one of evaluated parameters, was in prepared briquettes determined between $39-58 \%$. This way high participation of an iron is comparable with that one in minerals like limonite, chamosite or siderite.

\section{CONCLUSION}

Selected ladle slags represent various types characterizing changeable chemical and phase composition. This composition was formed based on use of various operating aggregates, type of actually producing steel and speed of slag cooling down. The most of ladle slags contain mainly $\mathrm{CaO}$ and relatively low $\mathrm{SiO}_{2}$. This composition is not suitable for an intensive glassy phase forming. Related to the origin of slags, suitable conditions for creation of amorphous phase are conditioned mainly by fast cooling of slag. During slow cooling slag crystalizes.

Related to required specific practical usage of achieved experimental results the possibility of water activation of ladle slags was evaluated predominantly. Based on study of their composition, mechanical parameters, evolution of hydration heat both raw materials and prepared solidified samples as well, it can be announced, that it is possible to activate chosen ladle slags by the effect of water. So that it is possible to use them as a binder and so they are suitable for a treatment of specific fine grain metal bearing waste products to bigger compact pieces in an order to recycle them for example in melting aggregates. An iron content in briquettes prepared with certain content of metal bearing wastes was carried on level 39-58 wt\%.

\section{ACKNOWLEDGEMENTS}

This research was supported from ERDF "Institute of Environmental Technology - Excellent Research, no. CZ.02.1.01/0.0/0.0/16_019/0000853. The authors Thank to Romana Švrčinová for her active participation on experimental works.

\section{REFERENCES}

[1] VLČEK, Jozef, FIEDOR, Jiří. Industrial wastes: Slags from iron and steel production. Ostrava: ECOFER, 1. edition, 2015.

[2] MOTZ, Heribert, et al. Products of steel slags an opportunity to save natural resources. Waste Management. 2001, vol. 21, no. 3, pp. 285-293.

[3] ŘEPKA, Vlastimil, et al. Wastes from iron and steel production and their recycling. Acta Metallurgica Slovaca. 2006, vol. 12, pp. 334-337.

[4] ALTAN, Ekin, et al. Alkali activation of a slag at ambient and elevated temperatures. Cement and Concrete Composites. 2012, vol. 34, no. 2, pp. 131-139.

[5] TOSSAVAINEN, Mia, et al. Characteristic of steel slag under different cooling conditions. Waste Management. 2007, vol. 27 , no. 10 , pp. 1335-1344. 